Erratum

\title{
Erratum to "Involvement of Nrf2-Mediated Upregulation of Heme Oxygenase-1 in Mollugin-Induced Growth Inhibition and Apoptosis in Human Oral Cancer Cells"
}

\author{
Young-Man Lee, ${ }^{1}$ Q-Schick Auh, ${ }^{2}$ Deok-Won Lee, ${ }^{3}$ Jun-Yeol Kim, ${ }^{1}$ Ha-Jin Jung, \\ Seung-Ho Lee, ${ }^{4}$ and Eun-Cheol Kim ${ }^{1}$ \\ ${ }^{1}$ Department of Maxillofacial Tissue Regeneration and Research Center for Tooth \& Periodontal Regeneration, \\ School of Dentistry, Kyung Hee University, Hoegi-dong, Dongdaemun-gu, Seoul 130-701, Republic of Korea \\ ${ }^{2}$ Department of Oral Medicine, School of Dentistry, Kyung Hee University, Hoegi-dong, Dongdaemun-gu, \\ Seoul 130-701, Republic of Korea \\ ${ }^{3}$ Department of Oral and Maxillofacial Surgery, School of Dentistry, Kyung Hee University, Hoegi-dong, Dongdaemun-gu, \\ Seoul 130-701, Republic of Korea \\ ${ }^{4}$ College of Pharmacy, Yeungnam University, Gyeongsan 712-749, Republic of Korea
}

Correspondence should be addressed to Eun-Cheol Kim; eckim@khu.ac.kr

Received 1 May 2014; Accepted 20 May 2014; Published 14 July 2014

Copyright (C) 2014 Young-Man Lee et al. This is an open access article distributed under the Creative Commons Attribution License, which permits unrestricted use, distribution, and reproduction in any medium, provided the original work is properly cited.

In the original paper, there were a number of errors in Figures 4 and 7. Here, we provide the right form of these figures. In Figure 4(a), p-JNK panels were the same in the HN4 and $\mathrm{HN} 12$ cells. In Figure 4(d), vertical, light streaks were included in the p-JNK panel of HN4 during the scanning of $\mathrm{X}$-ray film. In Figure 7(c), vertical, light streaks were included in the NF- $\kappa$ B p65 nuclear panel of HN4 during the scanning of X-ray film. 

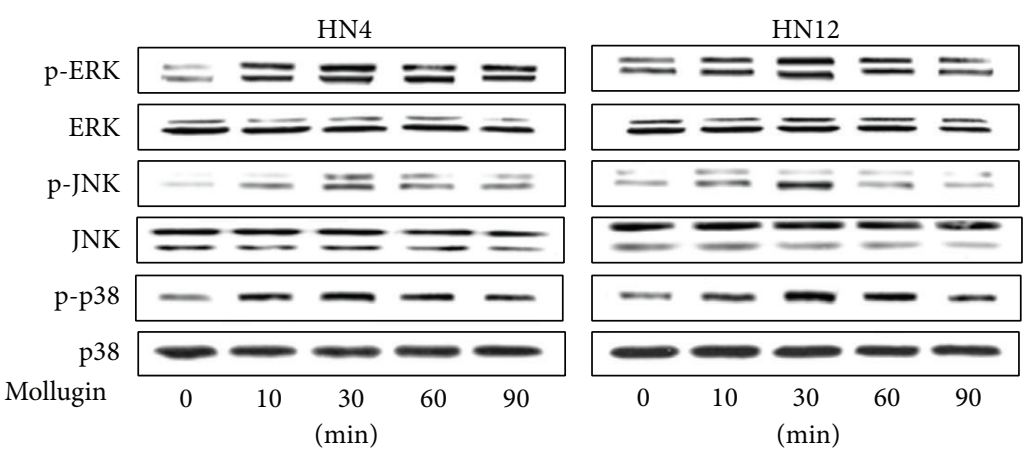

(a)
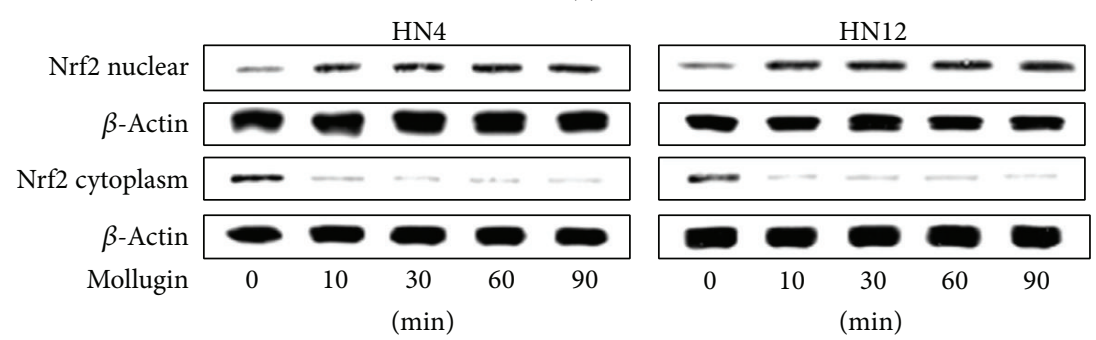

(b)
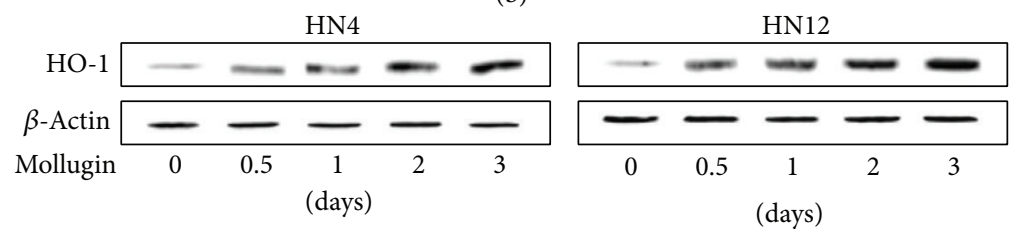

(c)
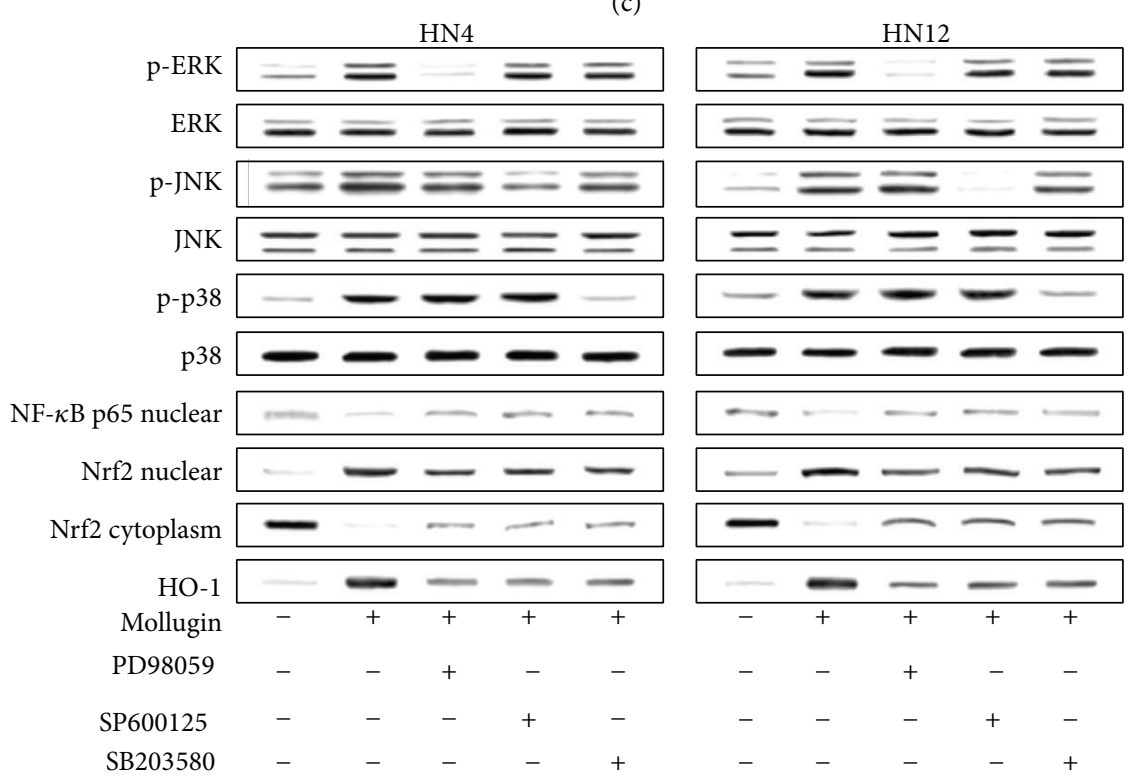

(d)

FIGURE 4: Effect of mollugin on phosphorylation of MAPK (a), activation of Nrf2 (b), and expression of HO-1 (c) in OSCCs. Effects of MAP kinase inhibitors on mollugin-induced activation of NF- $\kappa \mathrm{B}, \mathrm{Nrf} 2$, and $\mathrm{HO}-1$ (d). Cells were treated with $40 \mu \mathrm{M}$ mollugin for indicated times (a)-(c). Cells were pretreated with the p38 inhibitor SB203580 $(20 \mu \mathrm{M} / \mathrm{L})$, the ERK inhibitor PD98059 $(20 \mu \mathrm{M} / \mathrm{L})$, or the JNK inhibitor SP600125 $(20 \mu \mathrm{M} / \mathrm{L})$ for 1 hour and treated with $40 \mu \mathrm{M}$ mollugin for $30 \mathrm{~min}$ (MAPK, Nrf2, and NF- $\kappa \mathrm{B}$ ) or 3 days (HO-1). The results are representative of three independent experiments. 


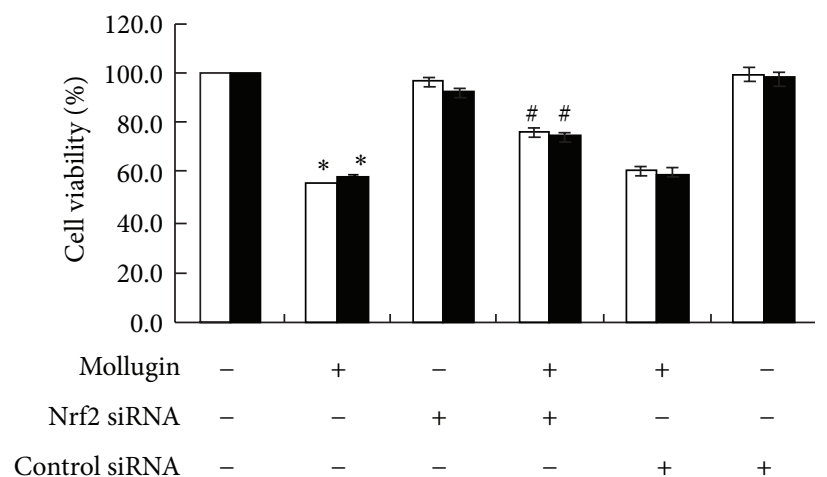

Control siRNA

\section{$\mathrm{HN} 4$}

HN12

(a)

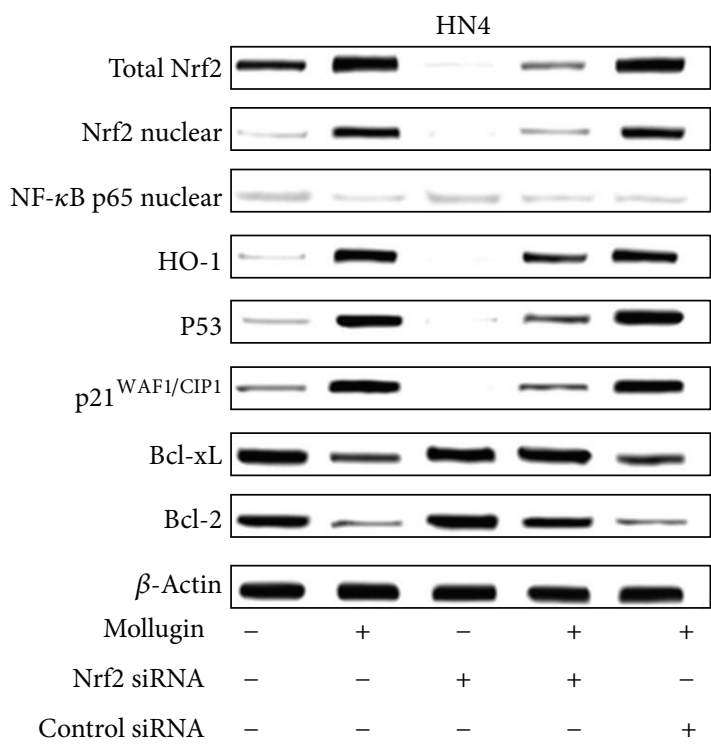

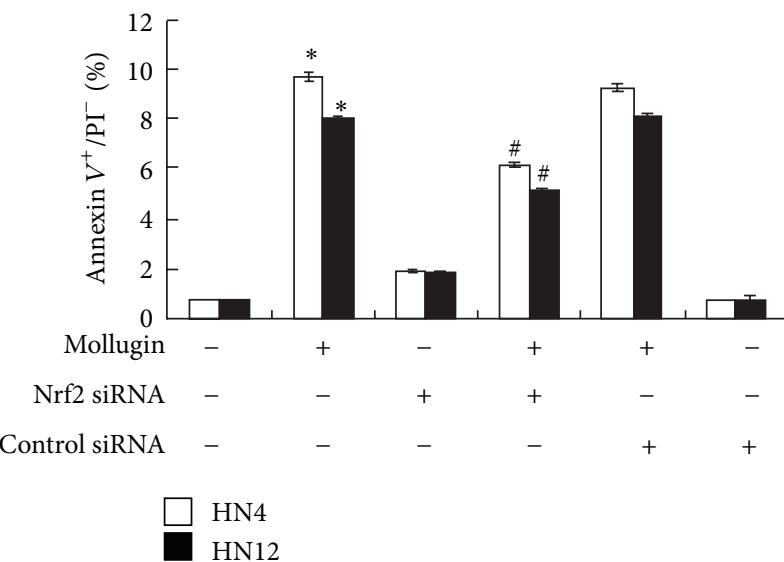

(b)

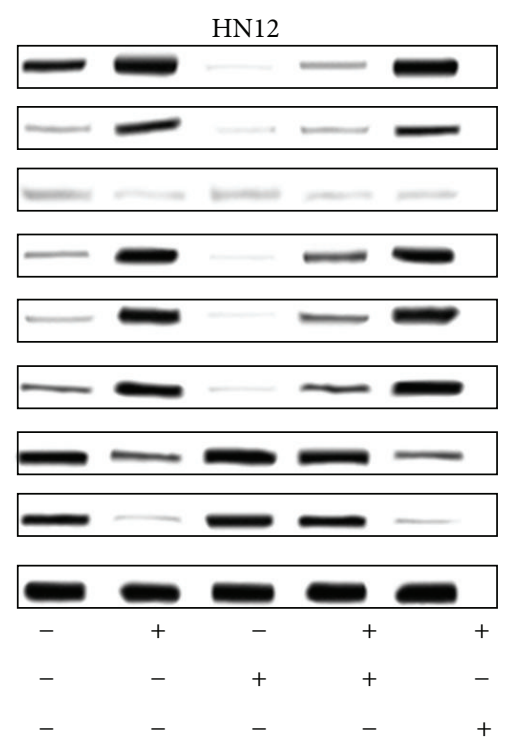

(c)

FIGURE 7: Effect of Nrf2 siRNA on mollugin-induced growth inhibition (a), apoptosis (b), and apoptosis-related proteins expression (c). Cells were treated with $40 \mu \mathrm{M}$ mollugin for indicated times (a). Cells were pretreated with Nrf2 siRNA ( $250 \mathrm{nM})$ for $5 \mathrm{~h}$ and treated for 3 days with mollugin $40 \mu \mathrm{M}(\mathrm{a}-\mathrm{c}) .{ }^{*}$ Statistically significant difference as compared to control, $P<0.05$. ${ }^{\#}$ Statistically significant difference as compared to mollugin, $P<0.05$. Data are representative of 3 independent experiments. 

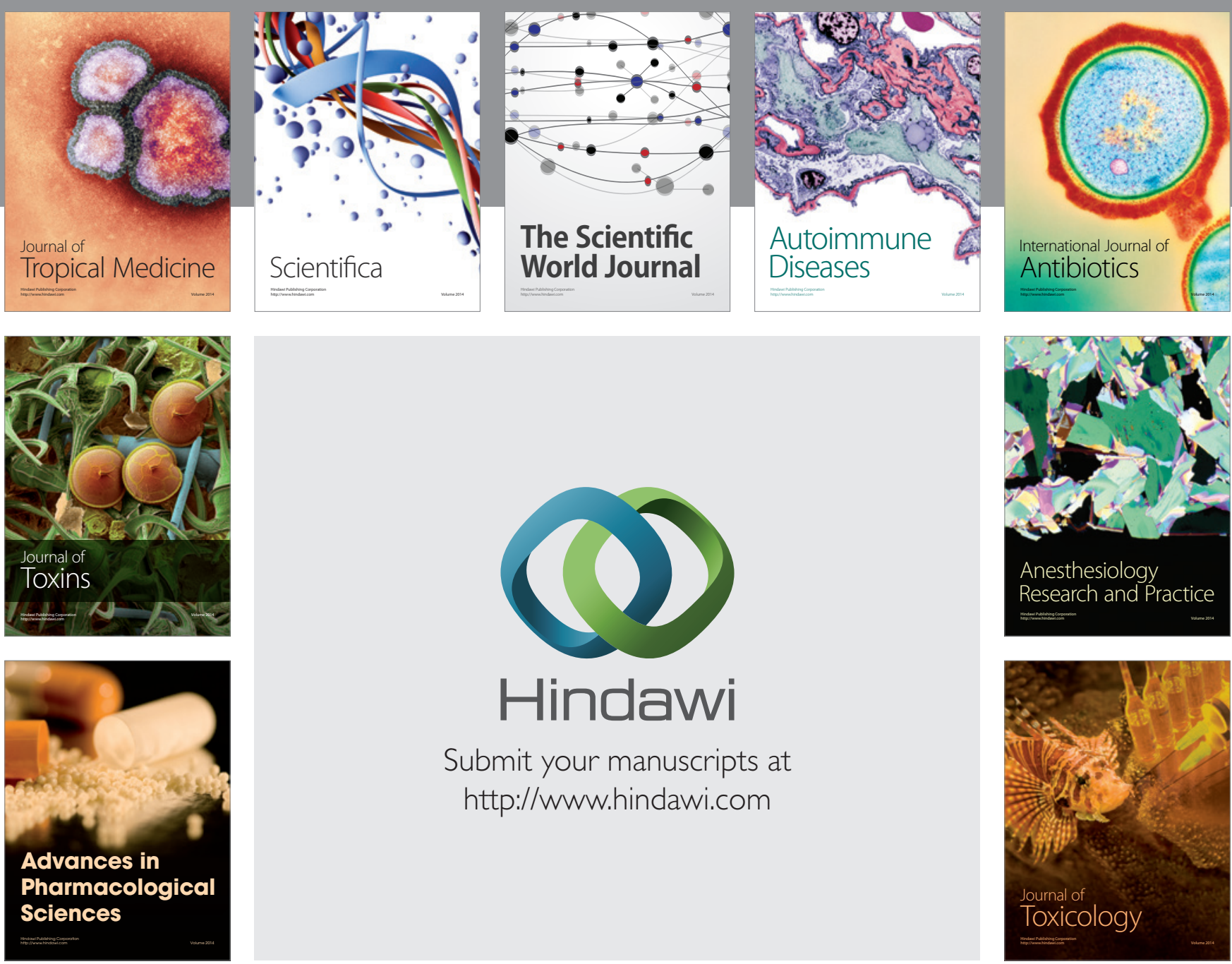

\section{Hindawi}

Submit your manuscripts at

http://www.hindawi.com
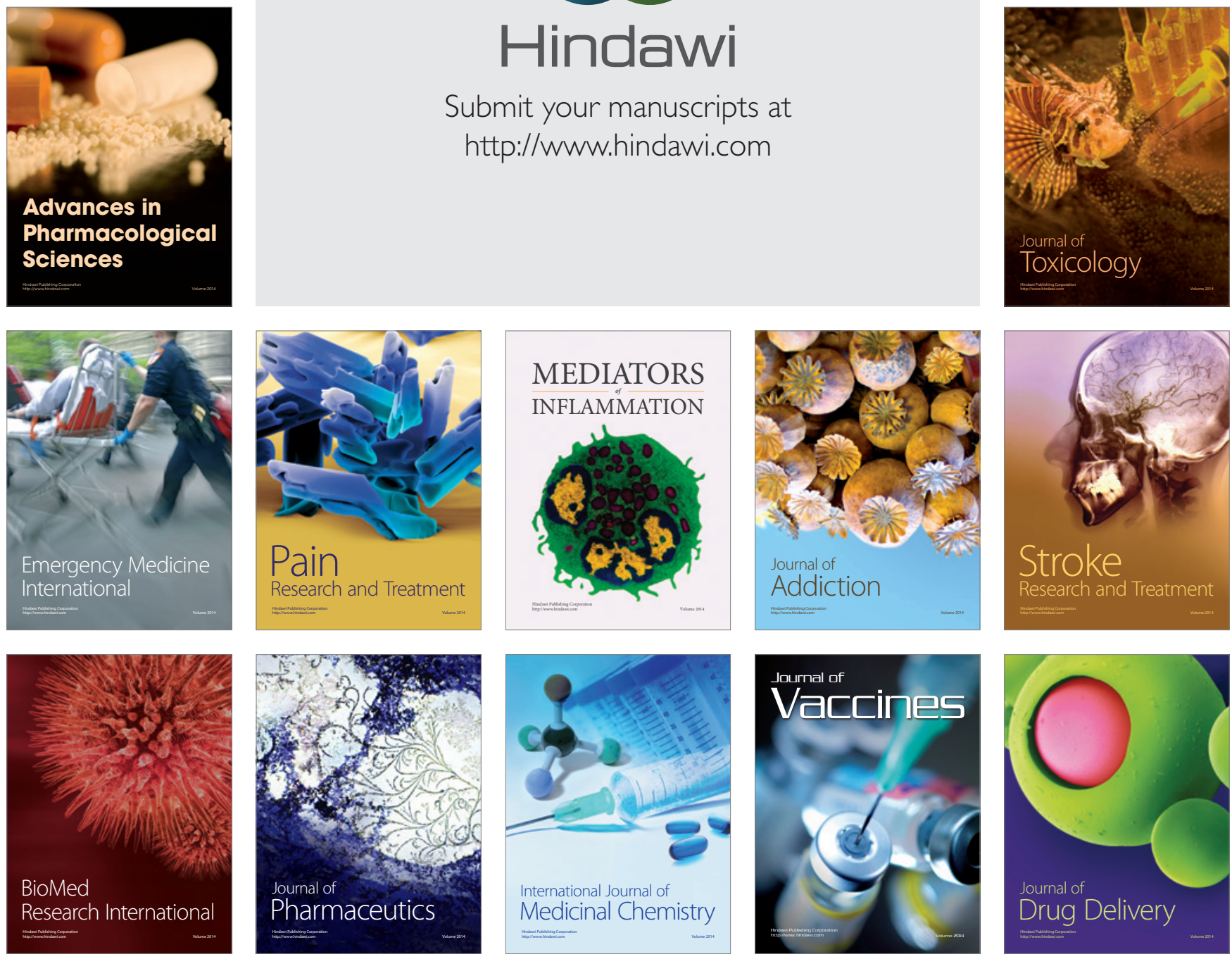